\title{
Developing Creativity Through Creative Engagement in Art Appreciation: Outcomes in Teaching Humanities
}

Prof. Ma. Cecilia Detosil-Alimen, PhD

Full Professor, College of Liberal Arts, Sciences, and Education

University of San Agustin, Iloilo City

mcalimen@usa.edu.ph

Pinky Jasmin A. Poral, PhD

Academic Supervisor, Languages, Humanities \& Literature

, College of Liberal Arts, Sciences, and Education

University of San Agustin, Iloilo City

pporal@usa.edu.ph

Rhounella Rhane S. Magpantay

Faculty, College of Liberal Arts, Sciences, and Education

University of San Agustin, Iloilo City

rmagpantay@usa.edu.ph

\section{Rosella Tady-Quiros}

Faculty, College of Liberal Arts, Sciences, and Education

University of San Agustin, Iloilo City

rosellaquiros@yahoo.com

\section{Ma. Elena Azarcon}

Faculty, College of Liberal Arts, Sciences, and Education

University of San Agustin, Iloilo City

Mayalena31fsa@gmail.com

DOI: http://doi.org/ 10.36892/ijlls.v3i4.718

\begin{tabular}{|c|c|}
\hline $\begin{array}{l}\text { Received: } \\
\text { 26/09/2021 }\end{array}$ & $\begin{array}{l}\text { Abstract } \\
\text { This descriptive-correlational study determined the level of creative engagement as }\end{array}$ \\
\hline $\begin{array}{l}\text { Accepted: } \\
\text { 02/11/2021 }\end{array}$ & $\begin{array}{l}\text { part of humanities teaching in the outcome-based education. This focuses on the } \\
\text { dimension of student engagement and creativity in the context of a new approach to } \\
\text { teaching and learning primarily through the arts. This study captures student creative } \\
\text { engagement supported by their personal reflection after the course term. There were }\end{array}$ \\
\hline $\begin{array}{l}\text { Keywords: } \\
\text { Iloilo City, } \\
\text { creativity, } \\
\text { engagement, } \\
\text { humanities, } \\
\text { art } \\
\text { appreciation }\end{array}$ & $\begin{array}{l}\text { eight (8) classes utilized with } 134 \text { students. Results showed that the level of students' } \\
\text { creativity in art appreciation was "high" and it was also "high" when they were } \\
\text { grouped as to sex. Creative engagement in art appreciation was considered "highly } \\
\text { influential" and it was "highly influential" when they were grouped as to sex. No } \\
\text { significant difference was noted in the level of the students' creative engagement and } \\
\text { development of creativity. There was a moderate and positive correlation between the } \\
\text { level of the students'creative engagement and influence of creative engagement in art } \\
\text { appreciation classes to their development of creativity. The most highly valued } \\
\text { creative engagement practices of students in art appreciation are: "I have developed } \\
\text { an appreciation for the local arts;" "I have deepened my sensitivity of myself, my } \\
\text { community and the society," and "Inclusion of art activities demonstrated my } \\
\text { understanding of art appreciation. }\end{array}$ \\
\hline
\end{tabular}




\section{INTRODUCTION}

The Commission on Higher Education (CHED) Retooling for University Professors has emphatically challenged tertiary teachers to enhance their teaching of humanities. The researchers, in their response to address such challenges in teaching art appreciation, saw the need to also achieve the outcome-based education demand. In this paper, the researchers utilized art appreciation students and engaged them into creative activities for the whole term to address some learning outcomes stated in the course syllabus.

In this context, part of the course outcomes explicitly includes the artistic development of students. Greater emphasis is still put on artistic expression apart from developing art appreciation. They are also expected to work effectively and independently in multidisciplinary and multi-cultural teams. They need to use appropriate theories and methodologies critically and creatively. Aside from that, they are also encouraged to use appropriate theories and methodologies critically and creatively as well as produce creative or critical texts in one of the genres that may be useful to literature as a discipline as an individual or group work not to mention the Augustinian Graduate Attributes. As Augustinian graduates, students are expected to be transformative community builder oriented towards God, critical and creative thinker, and social communicator of the Truth.

By CREATIVE ENGAGEMENT, creativity takes the purposeful involvement effort to make some artwork, meaningful expressions of themselves while in their art appreciation classes. Thus, as part of teaching art appreciation, students are exposed to a variety of activities. They are given opportunities to view different art works, understand, enjoy, and most of all analyze them using the different art theories. They are also given the chance to express themselves through their own unique interpretations of how they perceive works of art.

\section{LITERATURE REVIEW}

Teachers of art appreciation try different strategies to help students develop creativity in the course for them to maximize learning and at the same time achieve the skills and competencies required by the course. Studies have proved that art integrating more creativity improves student outcomes.

In 2017, the Commission on Higher Education (CHED) mandates the teaching of Art appreciation in the tertiary level as part of its General Education curricula. As such, it comprises 3 units and aims at developing students' ability to appreciate, analyze, and critique works of art. In fact, the teaching of this subject needs to be interdisciplinary and multimodal. This course also includes knowledge of the practical, historical, philosophical, and social relevance of the arts so as to develop their ability to express their understanding of the arts. Moreover, this allows students to develop competencies in doing research, curating art, conceptualizing, mounting, and evaluating art productions. Likewise, it aspires to develop, their authentic appreciation for Philippine arts by giving them avenues to explore the diversity and richness of the Filipino culture (CHED, 2017).

The teaching of art appreciation utilizes approaches to realize the objectives set forth in the curriculum. In a study by Therunavukarasu (2021), the impact of the art class on students was investigated. It asserts that art has been a tool to foster critical-thinking skills and also aids in problem solving. In fact, by exploring, experimenting, and reasoning play a significant role in an art curriculum.

In the study, Gender and creativity: an overview of psychological and neuroscientific literature by Abraham (2015), it highlights that a creative response or product is one that is determined to be both original and relevant (Runco and Jaeger, 2012). And that she adds that creativity refers to the singularly complex human capacity to produce novel ideas, generate new solutions, and express one- self in a unique manner. Although astounding works of art and groundbreaking scientific discoveries are the customary associations that are readily evoked 


\section{Humanities}

when the concept of creativity is considered, the capacity to be creative is evident in virtually all aspects of human life when engaged in language and communication, choice and decision making, as well as planning and organization (Runco and Pritzker 2011; Sawyer 2012). While the potential to be creative exists within each person (regardless of his or her gender), there is considerable individual variability in both the type and amount of creative output that is produced over a lifetime.

In Beghetto and Kaufman's (2010) study, they express their hopes that educators may have the opportunity to find their students' potential for creativity. They said that to achieve this ambitious goal the collaborated with their 26 colleagues who are going to observe their students. In this same study the creativity conceptualization focuses on everyday creativity they were able to articulate four strands of creativity mini c (interpretive creativity), little c (everyday creativity) pro c (professional creativity) and big c (legendary creativity). Such were perceived to pertinent in the classroom. In addition, that, teachers must take the challenge to sustain students' creative potential at the heart of the educational enterprise. In another study, a focus on the festival and ceremony as objects of investigation (Jamgbadi, 2021; Rahim \& AlSaggaf, 2021) can also be worth studying in art appreciation integrated with art as expression. Such can even be utilized as subjects of art, an aspect that students in art appreciation can also explore.

\subsection{Research Questions}

This present study determined the level of creative engagement of art appreciation students as evidenced by the survey conducted for this purpose and supported by their reflections about the conduct of the humanities classes. This likewise addressed the following questions:

1. What is the level of the students' creative engagement in art appreciation classes as an entire group and when grouped according to sex?

2. What is the influence of creative engagement in art appreciation classes to students' development of creativity?

3. Is there a significant difference in the level of the students' creative engagement in art appreciation classes when they were grouped according to sex?

4. Is there a significant difference in the influence of creative engagement in art appreciation classes to students' development of creativity when they were grouped according to sex?

5. Is there a correlation between the level of creative engagement and influence of creative engagement to development of creativity?

6. What creative engagement practices are highly valued by the students?

\subsection{Significance of the Study}

This study will provide higher education teachers evidence on the benefits of engaging art appreciation students to creative engagement during their humanities classes. This investigation will motivate them to utilize further creative engagement in their courses to ensure learning even in non-humanities classes.

This study can also encourage students to develop artistic and creative skills and may be able to hone their talents to channel their energies and be proactive and productive, especially in these difficult times.

The institution may be provided with the results of this investigation and may provide collaborative and multidisciplinary projects to promote creative engagements and cultural practice in the school community.

\section{METHODOLOGY}

3.1. Research Design 
This study utilized the descriptive-correlational design. Descriptive studies examine the status of individuals, institutions, or processes. Descriptive research design was used to estimate the extent to which different variables are related to one another. The elements of this design include the identification of the variables of interest, the group of subjects/ respondents where the variables were applied and the estimation procedure to determine the extent of relationship (Padua, 2000).

Meanwhile, a correlation design was utilized as the researchers sought to find out the extent of relationship between the different variables under study. A correlation research, sometimes known as associational research measures the extent of magnitude of association between two variables (Vizcarra, 2009).

The appropriateness of this design is based on the main purpose of this study which is to determine the correlation of the level of creative engagement and its influence to the development of creativity of the students in art appreciation.

\subsection{Participants of the Study}

The respondents of this study were the 134 purposively selected art appreciation students during the second semester of school year 2019-2020. The respondents were enrolled in art appreciation of the current semester. Purposive sampling was utilized as the researchers purposely determined the number of respondents in each section until the desired number of sample was reached.

The respondents were classified only according to sex. There were 46 males and 88 females. The students were from different courses such as tourism, marketing management, nursing, medical laboratory science, education, and pharmacy. At least ten per cent (10\%) of the students enrolled have not answered the questionnaire due to the pandemic.

\subsection{Sampling Technique}

For this study, simple random sampling was employed. It is a type of probability sampling method in which the teachers handling art appreciation subjects were selected and after which their students were identified as to number. The researchers gave each of the students' names a chance to be picked as respondents. Each of the teachers was requested to submit the names of their students picked from the group (population) after the researchers finally computed the definite number of samples.

\subsection{Data Gathering Procedure}

Data were collected through the use of a modified instrument on Creativity Engagement. The instrument has three (3) parts. Part 1 shows the personal profile of the respondents. Part 2 contains the Level of Creative Engagements consisting of ten (10) statements answerable by Strongly Agree (SA), Agree (A), Neutral (N), Disagree (D), Strongly Disagree (SD).

Part 3 contains the Influence of Creative Engagements consisting of ten (10) statements also answerable by Strongly Agree (SA), Agree (A), Neutral (N), Disagree (D), Strongly Disagree (SD). For statistical purposes, numerical weights were respectively assigned to the responses as follows: Strongly Agree - 5, Agree - 4, Neutral - 3, Disagree - 2, and Strongly Disagree - 1. To determine the level of creative engagement and its influence on the development of student creativity, the following descriptive levels based on arbitrary scaling were employed.

$\begin{array}{lll}\text { Scale } & \begin{array}{l}\text { Description } \\ \text { (Level of Creative } \\ \text { Engagement) }\end{array} & \begin{array}{l}\text { Description } \\ \text { (Influence to } \\ \text { Development of } \\ \text { Creativity) }\end{array} \\ 4.21-5: 00 & \text { Very High } & \begin{array}{l}\text { Very Highly Influential } \\ \text { Highly Influential }\end{array} \\ 3.41-4.20 & \text { High } & \begin{array}{l}\text { Influential } \\ 2.61-3.40\end{array} \\ \text { Moderate } & \end{array}$



$1.81-2.60$
Low
Less Influential
$1.00-1.80$
Very Low
Not Influential

Ethical consideration is an important aspect in research. This is called as a researcher's accountability for their actions. This ensures the public that they can trust the research being done. This also supports social and moral values, such as the principle of doing no harm to others.

In carrying out this action research, the researchers informed the respondents that their participation to the research is voluntary and that are given freedom to whether participate or not and they can withdraw their consent and discontinue participation at any time without prejudice.

To interpret the data, descriptive statistics such as frequency count, percentage, mean, and standard deviation were used to describe distributions and relationships between variables (Best and Kahn, 2012). The data gathered from the accomplished questionnaires were examined, classified and analyzed according to the objectives of the study. Responses were tabulated, tallied, and interpreted. Inferential statistics such as t-test and Pearson's $r$ were also utilized in this study.

\section{RESULTS AND DISCUSSIONS}

Level of the Students' Creative Engagement in Art Appreciation Classes as an Entire Group and when Grouped according to Sex

Results show that when taken as an entire group, the level of the students' creative engagement in art appreciation classes is considered high $(\mathrm{M}=4.44, \mathrm{SD}=0.35)$. When grouped according to sex, both male $(\mathrm{M}=4.44, \mathrm{SD}=0.33)$, and female $(\mathrm{M}=4.44, \mathrm{SD}=0.36)$. Respondents rated the level of the students' creative engagement in art appreciation classes as high. Table 1 reflects the data.

Table 1. Level of the Students' Creative Engagement in Art Appreciation Classes as an Entire Group and When Grouped according to Sex

\begin{tabular}{lcccc}
\hline Sex & Mean & $\mathrm{N}$ & SD & Interpretation \\
\hline Male & 4.44 & 46 & .33 & High \\
Female & 4.44 & 88 & .36 & High \\
Total & 4.44 & 134 & .35 & High \\
\hline
\end{tabular}

Legend: 1-1.50 - Very Low 1.51-2.50 - Low 2.51-3.50 - Moderately High 3.51-4.50 - High 4.51-5 - Very High

Influence of Creative Engagement in Art Appreciation Classes to Students' Development of Creativity

When taken as an entire group, creative engagement in art appreciation classes to students' development of creativity is considered highly influential $(\mathrm{M}=4.25, \mathrm{SD}=0.30)$. When group according to sex, both male $(\mathrm{M}=4.22, \mathrm{SD}=0.27)$ and female $(\mathrm{M}=4.26, \mathrm{SD}=0.32)$. Respondents rated the influence of creative engagement in art appreciation classes to students' development of creativity as highly influential. Table 2 shows the data.

Table 2. Influence of Creative Engagement in Art Appreciation Classes to Students' Development of Creativity

\begin{tabular}{lcccc}
\hline Sex & Mean & $\mathrm{N}$ & SD & Interpretation \\
\hline Male & 4.22 & 46 & .27 & Highly Influential \\
Female & 4.26 & 88 & .32 & Highly Influential \\
Total & 4.25 & 134 & .30 & Highly Influential \\
\hline
\end{tabular}


Note: 1-1.50 - Not Influential 1.51-2.50 - Less Influential 2.51-3.50 - Influential 3.51-4.50 Highly Influential 4.51-5 - Very Highly Influential

Majority of the reflections from the students include their views like it gives me the freedom to express myself; it enhances my artistic ability through working with others; I developed my confidence in doing art; It developed my creativity and appreciate the local arts; I constructed meaning and articulated my thoughts my personal expressions, among others.

Undeniably, students' engagement in art appreciation classes has in one way or the other helped them developed their creativity. Apparently, one student said, my creative engagement in art appreciation enhanced my skills and unlocked my potential in crafts that I did not know, I possess before I took the class. Some of the students have in fact stated that had it not for the art appreciation class, they were not able to showcase their art products. They were proud of their participation during the Art Exhibit. Their reflection stated that Art Appreciation was the best as it made them realize their potentials as students and they were able to prove that there is an artist in them.

\section{Difference in the Level of the Students' Creative Engagement in Art Appreciation Classes when they were Grouped According to Sex}

Results show the not significant difference in the level of the students' creative engagement in art appreciation classes when they were grouped according to sex, $U=2008.000$, $\mathrm{p}=0.940$. A probability of 0.940 is greater than 0.05 . Therefore, the null hypothesis must not be rejected. The level of the students' creative engagement in art appreciation classes when they were grouped according to sex does not vary. Table 3 shows the data.

Table 3. Difference in the level of the students' creative engagement in art appreciation classes when they were grouped according to sex

\begin{tabular}{llcccc}
\hline \multicolumn{1}{c}{ Sex } & $\mathrm{N}$ & $\mathrm{U}$ & Asymp. Sig. (2-tailed) & Interpretation \\
\hline Level & Male & 46 & 2008.000 & 0.940 & Not \\
& Female & 88 & & & Significant \\
& Total & 134 & & & \\
\hline $\mathrm{p}<.05$ & & & & &
\end{tabular}

Thus, this implies that students' creative engagement is inherent in each one and that both male and female students consider creative engagement as an opportunity to express their artistic ability. In the study, Gender and creativity: an overview of psychological and neuroscientific literature by Abraham (2015), it highlights that a creative response or product is one that is determined to be both original and relevant (Runco and Jaeger, 2012). And that she adds that creativity refers to the singularly complex human capacity to produce novel ideas, generate new solutions, and express one- self in a unique manner. Although astounding works of art and groundbreaking scientific discoveries are the customary associations that are readily evoked when we consider the concept of creativity, our capacity to be creative is evident in virtually all aspects of human life when engaged in language and communication, choice and decision making, as well as planning and organization (Runco and Pritzker 2011; Sawyer 2012). While the potential to be creative exists within each person (regardless of their gender), there is considerable individual variability in both the type and amount of creative output that is produced over a lifetime. 
Difference in the Influence of Creative Engagement in Art Appreciation Classes to Students' Development of Creativity when they were Grouped according to Sex

Results show the not significant difference in the influence of creative engagement in art appreciation classes to students' development of creativity when they were grouped according to sex, $\mathrm{U}=1867.500, \mathrm{p}=0.461$. A probability of 0.461 is greater than 0.05 . Therefore null hypothesis must not be rejected. The influence of creative engagement in art appreciation classes to students' development of creativity when they were grouped according to sex does not vary. Table 4 shows the data.

Table 4. Significant difference in the influence of creative engagement in art appreciation classes to students' development of creativity when they were grouped according to sex

\begin{tabular}{llcccc}
\hline & Sex & $\mathrm{N}$ & $\mathrm{U}$ & Asymp. Sig. (2-tailed) & Interpretation \\
\hline Influence & Male & 46 & 1867.500 & 0.461 & Not \\
& Female & 88 & & & Significant \\
& Total & 134 & & & \\
\hline $\mathrm{p}<.05$ & & & & &
\end{tabular}

Similarly, there is not significance in the influence of creative engagement in art appreciation classes to students' development of creativity when they were grouped according to sex. To reiterate Abraham (2015), she emphasized that further research is essential to verify the manner and the degree to which gender-based strategy differences explain variations in creative (and indeed non-creative) performance. She adds that one means by which this can be done is by having participants report what kind of strategies they were explicitly aware of using during the creative idea generation phase. To investigate implicit strategy differences, the consistency of the pattern of brain activity differences during task performance as a function of gender can be compared across different studies.

With this, Abraham concluded in her study that assessing gender differences in creativity is a controversial line of research to explore. And for good reason. That is, it is naïve and wrong to suggest either that one gender is more creative than another, or that there are absolutely no differences between the sexes (Pinker, 2009). The truth appears to be far more nuanced and complex as Pinker puts it. In bringing together diverse bodies of evidence that have explored gender differences in cognition and brain function, the take-home message from this overview is that the sexes do not differ in terms of global or specific intellectual abilities but may do so in the cognitive strategies, functional task sets or cognitive styles that each are physiologically predisposed to adopt. These tentative insights point to novel avenues that beg further exploration in the field of gender differences in creativity. This is a better description of the non-significant difference of creativity between males and females. Reflections of both male and female lead to the fact that creative engagement has influenced creativity to both sexes as expressed in the following statements: I was able to express my thoughts and expressed my emotions; the value of art and how it helped me develop mine in a unique way; working with my groupmates and exchanging our ideas lead to more creative juices and finally an excellent artistic product; creative engagement has widened my mind and made me see the beauty of each and the world around me, etc. 


\section{Correlation between the Level of Creative Engagement and Influence of Creative Engagement to development of Creativity}

Results show that there is a moderate, positive correlation between the level of the students' creative engagement in art appreciation classes and influence of creative engagement in art appreciation classes to students' development of creativity which is statistically significant $\left(r_{s}=0.469, n=1134, p=0.000\right)$. A probability of 0.000 is less than the level of significance which is 0.05 . Therefore, the null hypothesis is to be rejected. There is significant relationship between level of the students' creative engagement in art appreciation classes and influence of creative engagement in art appreciation classes to students' development of creativity. Table 5 reflects the data.

\section{Table 5. Correlation between the Level of Creative Engagement and Influence of Creative Engagement to Development of Creativity}

$$
\text { Level }
$$

\begin{tabular}{lccc} 
& $\mathrm{r}_{\mathrm{s}}$ & Sig. (2-tailed) & Interpretation \\
\hline Influence & $.469^{* *}$ & 0.000 & Significant \\
\hline
\end{tabular}

**. Correlation is significant at the 0.01 level (2-tailed).

The results of the study is more interesting as they show that there is a moderate, positive correlation between the level of the students' creative engagement in art appreciation classes and influence of creative engagement in art appreciation classes to students' development of creativity.

This result is supported by the students' reflections. One said, I have realized the essence of creative engagement. It has sharpened my skills to come up with a creative outcome and apply it in my life. Another said, I was able to showcase my talent in myself expression through singing and dancing. Learning techniques in art appreciation improve my creativity. Art appreciation has been a way for me to lessen my stress and helped me discover myself more. I was able to explore my thought and emotions. It enhanced my imagination and helped me realize that creativity can be developed through exposure and practice. Such reflections have proved that creative engagement and creativity go hand in hand. In every activity in art appreciation, my creativity is enhanced. It made me try things that I am not good at. It helped become more creative in doing stuff related with arts.

Amazingly, creative engagement not only helped students develop their creativity per se but it has also improved their mental health and psychological well-being. Some students underscored that where I can freely express my ideas into artwork and there is no right or wrong interpretation of my work, the activities transported me to a world where I am able to understand myself. Another touching reflection is, when I was able to create an artwork using my own ideas, it helped me value my creation. I was able to explore my thoughts and emotions, made me go out of my comfort zone, and helped others to become creative. I was able to improve my confidence. My experiences gave me internal appreciation of harmony and beauty of being human, etc.

It is significant to note that when students are being exposed to art appreciation activities, creativity is not the only skill that is being developed. The hidden curriculum is at play in this context. Another point worthy of discussion is how creative engagement draws out the Augustinian dimension among the students. Several of the students' reflections include: Working with others and exchanging ideas have brought out the best of us and a significant output has come out - our artwork. I have appreciated the beauty of diversity during our planning and art exhibit. The art exhibit was fun and cool with teammates. It revealed my desire to use and share my experience to others. To inspire action and become a voice for 


\section{Humanities}

others. To convey my own perspective and help people. Connect with others and create solutions to problems confronting our country. I saw my potential and those of my classmates.

Not only that, appreciation of local culture is also highlighted in the students' reflections. Doing plates made me appreciate my local culture. Art appreciation broadened my mind about culture and arts. Art appreciation helped me value art especially the local art found in my community among others. There is a positive and significant relationship between creative engagement and creativity. The students' reflection show that their engagement led to their creative development. Data from this study suggest that student creative engagement promote and improve creativity.

\section{Creative Engagement Practices that are Highly Valued by the Students}

Using the rank, the most highly valued creative engagement practices of students in art appreciation are: I have developed an appreciation for the local arts in Rank 1, I have deepened my sensitivity of myself, my community and the society in Rank 2, and, Inclusion of art activities demonstrated my understanding of art appreciation in Rank 3. These creative engagement practices were considered by art appreciation students as contributing to their development of creativity.

Table 6 reflects the data.

\section{Table 6. Creative Engagement Practices that are Highly Valued by the Students}

\begin{tabular}{lcccc}
\hline Item & N & Mean & SD & Rank \\
\hline $\begin{array}{l}\text { 1) Inclusion of art activities demonstrated my } \\
\text { understanding of art appreciation. }\end{array}$ & 134 & 4.5448 & .49986 & 2 \\
$\begin{array}{l}\text { 2) I was able to demonstrate the elements and } \\
\text { principles of design }\end{array}$ & 134 & 4.2836 & .62060 & 10 \\
$\begin{array}{l}\text { 3) My art activities have helped me evaluated the } \\
\text { theories of art. }\end{array}$ & 134 & 4.3806 & .48736 & 8.5 \\
$\begin{array}{l}\text { 4) Creative engagement is GE } 6 \text { has helped me } \\
\text { understood Philippine art in the global context. }\end{array}$ & 134 & 4.3806 & .48736 & 8.5 \\
$\begin{array}{l}\text { 5) I was able to analyze works of art based on } \\
\text { aesthetic value and historical context. }\end{array}$ & 134 & 4.4254 & .56697 & 6.5 \\
$\begin{array}{l}\text { 6) I have participated in the art exhibit applying the } \\
\text { principles of art learned in art appreciation. }\end{array}$ & 134 & 4.4254 & .62980 & 6.5 \\
$\begin{array}{l}\text { 7) I have expressed my creativity by creating my own } \\
\text { art works leading to the course exhibit. }\end{array}$ & 134 & 4.4478 & .62006 & 4.5 \\
$\begin{array}{l}\text { 8) I utilized art for self- expression and for promoting } \\
\text { my advocacies. }\end{array}$ & 134 & 4.4478 & .58254 & 4.5 \\
$\begin{array}{l}\text { 9) I have deepened sensitivity of myself, my } \\
\text { community and the society. }\end{array}$ & 134 & 4.4851 & .55840 & 3 \\
10) I have developed an appreciation for the local & 134 & 4.6045 & .49080 & 1 \\
arts. & & & & \\
\hline
\end{tabular}

\section{CONCLUSIONS}

Based on the findings, the following conclusions were advanced:

1) Students consider their creative engagement in art appreciation as high. A more consistent application of creative engagement in other courses may enhance their creativity in a more intensive manner and in a consistent process.

2) Creative engagement in art appreciation classes highly influenced their development of 
creativity. The students could also get more practice with creativity coupled with reflection in the art appreciation classes, and in more advanced perspectives use their creative skills to develop plans based on experience.

3) Students' creative engagement in art appreciation classes and development of creativity work hand in hand. The impact of students' creative engagements could have been further investigated by viewing the study over a whole school year with another group of students to compare the consistency of the results.

4) 4) Creative engagement in art appreciation classes highly influence students' development of creativity. More support (teachers) based on student feedback, and support students with deeper thinking about what components could be implemented in order to increase their understanding while keeping them engaged.

5) Creative engagement in art appreciation classes and development of creativity are significantly correlated. Students should be made to establish clear goals for themselves, using their reflections.

6) The highly valued creative engagement practices of students in art appreciation are aligned with the realization of the course outcomes as appreciation for the local arts; social responsibility (self, community, and society).

\section{IMPLICATIONS FOR EDUCATIONAL PRACTICE AND FOR FUTURE RESEARCH}

Art Appreciation teachers of higher education institutions need to engage their students in creative activities to enhance their creativity.

Activities can range from visual art plates, constructing, and painting to entirely create them an opportunity to enhance their appreciation for arts and further expose them to enriching artistic tasks.

This study also provides students with the opportunity to relate real-life context, culture, everyday life, and other aspects of their art integration requirements.

Furthermore, researchers can further investigate the appropriateness of creative engagement as a paradigm in the teaching of humanities and the realization of curriculum outcomes in the context of other methodologies.

Researchers may consider further studies on strategies to enhance humanities teaching and creative engagement.

\section{REFERENCES}

Abraham, A. (2015). Gender and creativity: an overview of psychological and neuroscientific literature. Brain Imaging and Behavior. Springer. DOI 10.1007/s11682-015-9410-8.

Beghetto, R. A. (2010). Creativity in the classroom. In J. Kaufman \& R. Sternberg (Eds.), The Cambridge handbook of creativity (pp. 447-467). New York: Cambridge University Press.

Beghetto, R. A. (2013). Killing ideas softly?: The promise and perils of creativity in the classroom. Charlotte, NC: IAP, Information Age Publishing, Inc.

Beghetto, R. A., \& Kaufman, J. C. (2010). Nurturing creativity in the classroom. Cambridge ; New York: Cambridge University Press.

Commission on Higher Education (2017). Art Appreciation Course. https://ched.gov.ph/wpcontent/uploads/2017/10/ARTAPPRECIATION.pdf.

Jamgbadi, E.I.(2021). Gender issues and space in Esan festivals and ceremonies. International Journal of Language and Literary Studies. 3(3), 268-274.

Inker, S. (2009). The sexual paradox: Men, women and the real gender gap. New York: Scribner. 


\section{Humanities}

Rahim, R. N. B. A. ., \& Al-Saggaf, M. A. (2021). Students' Perception Towards Flipped Classroom Approach in The Islamic And Asian Civilisation Studies (Titas). Journal of Translation and Language Studies, 2(1), 1-18. https://doi.org/10.48185/jtls.v2i1.135

Runco, M. A., \& Jaeger, G. J. (2012). The standard definition of creativity. Creativity Research Journal, 24(1), 92-96. doi:10.1080/ 10400419.2012.650092.

Sawyer, R. K. (2012). Explaining creativity: The science of human innovation (2 ed.). New York: Oxford University Press.

Therunavukarasu, M. (2021). The Impact of Art Class on Students. https://www.owis.org/blog/the-impact-of-art-class-on-students on September 24, 2021.

\section{AUTHORS' BIO}

Prof. Ma. Cecilia Detosil-Alimen, PhD is a Full Professor at the University of San Agustin, Iloilo City. She teaches in the undergraduate and the graduate levels. She has presented research papersin various conferences in both local and international conferences across Asia and the United States of America. Recently, she got the Most Influential Teacher award from the United Filipino-American Educators (UNIFFIED) United States of America. She got her Master of Education in English and Master of Education in Special Education from West Visayas State University in 1999 and 2015 respectively and her Doctor of Philosophy in English Studies: Language from the College of Arts and Letters, University of the Philippines-Diliman Quezon City in 2004.

Pinky Jasmin A. Poral, PhD is an Associate Professor and the Academic Supervisor of the Languages, Humanities and Literature and the Bachelor of Arts in Literature Program, at the College of Liberal Arts, Sciences, and Education, University of San Agustin, Iloilo City. She earned her Master of Arts in Education, major in Language Teaching English from West Visayas State University and her Doctor of Philosophy in Educational Management at The University of San Agustin. She has also presented her research papers in conferences, both local and abroad. She also had trainings as Professional Development for Teacher Trainer by Arizona State University, TESOL of the University of Maryland, and ASEAN Teachers \#UpskillwithAU of the Universities of Queensland and Sydney.

Rhounella Rhane S. Magpantay MAEd SPED, LPT, is an instructor III of the College of Liberal Arts, Sciences, and Education at the University of San Agustin, Iloilo City. She earned her Master of Arts in Special Education from Centro Escolar University in 2013 and obtained her Diploma in Teaching in 2019 from West Visayas State University. She has participated in researches as a panelist in undergraduate and graduate school programs and co-author in a collaborative research in Art Appreciation.

Rosella Tady-Quiros, MAEd, LPT is an Assistant Professor of the College of Liberal Arts, Sciences, and Education at the University of San Agustin, Iloilo City. She earned her Master of Arts in Education, major in Reading from West Visayas State Univeristy. She has presented her research papers in both local and international conferences. Her last presentation before the pandemic was in Indonesia and Taiwan.

Ma. Elena S. Azarcon, MAT, RN, LPT is an Assistant Professor of the College of Liberal Arts, Sciences, and Education at the University of San Agustin, Iloilo City. She teaches language and humanities in the undergraduate level. She earned her Master of Arts in Education, major in Language Teaching English from West Visayas State University, Iloilo City, Philippines. She has also taught English in Tainan, Taiwan. 